\title{
Digestibilidade e características ruminais de dietas com diferentes níveis de concentrado para bubalinos e bovinos ${ }^{1}$
}

\author{
Emilyn Midori Maeda ${ }^{3}$, Lúcia Maria Zeoula ${ }^{2}, 5$, Luiz Juliano Valério Geron ${ }^{3}$, Jeroen de Best ${ }^{4}$, \\ Ivanor Nunes do Prado ${ }^{2,5}$, Elias Nunes Martins ${ }^{2,5}$, Ricardo Kazama ${ }^{3}$

\footnotetext{
1 Parte da dissertação da primeira autora apresentada à Universidade Estadual de Maringá para obtenção do título de "Mestre em Zootecnia".

2 Departamento de Zootecnia - UEM, Av. Colombo, 5790. CEP: 87020-900, Maringá-PR.

3 Pós-Graduação em Zootecnia - UEM, Av. Colombo, 5790. CEP: 87020-900, Maringá-PR.

${ }^{4}$ Graduação em Zootecnia - Bolsista PIBIC - UEM, Av. Colombo, 5790. CEP: 87020-900, Maringá-PR.

${ }^{5}$ Pesquisador do CNPq.
}

RESUMO - Avaliaram-se a influência do fornecimento de 23, 43 e $63 \%$ de concentrado em dietas com milho moído e resíduo desidratado de mandioca como fonte de amido sobre o consumo, os coeficientes de digestibilidade total e parcial dos nutrientes, a concentração de amônia, o pH ruminal e a eficiência microbiana. Utilizaram-se três bovinos holandeses (Bos taurus) e três búfalos Murrah (Bubalus bubalis) com $473 \pm 54 \mathrm{~kg}$ e $400 \pm 33 \mathrm{~kg}$ de peso corporal (PC), respectivamente, canulados no rúmen e duodeno. Os fluxos duodenais e fecais foram estimados utilizando-se óxido crômico. O delineamento experimental utilizado foi com dois quadrados latinos $3 \times 3$ e arranjo fatorial $3 \times 2$. A ingestão média de MS foi inferior nos bubalinos $(1,40 \%$ do PC) em comparação aos bovinos (1,63\% do PC). As ingestões máximas de $\mathrm{PB}\left(10,09 \mathrm{~g} / \mathrm{kg} \mathrm{PC} \mathrm{PC}^{0,75}\right.$ nos bovinos e $8,36 \mathrm{~g} / \mathrm{kg} \mathrm{PC}$ P,75 $^{0,75}$ nos bubalinos) foram obtidas com $44,4 \%$ de concentrado e as de amido $\left(32,83 \mathrm{~g} / \mathrm{kg} \mathrm{PC} \mathrm{PC}^{0,75}\right.$ para os bovinos e $28,38 \mathrm{~g} / \mathrm{kg} \mathrm{PC}^{0,75}$ para os búfalos), com $61,7 \%$ de concentrado. Os coeficientes de digestibiliade total e as digestibilidades ruminal (DR) e intestinal (DI) dos nutrientes, à exceção do amido e da $\mathrm{PB}$, não diferiram entre os tratamentos e as espécies utilizadas. $\mathrm{O}$ maior coeficiente de digestibilidade total $(95,7$ vs $85,8 \%)$ e ruminal $(87,4$ vs $81,9 \%)$ do amido foram observados nos bovinos. A digestibilidade ruminal do amido aumentou linearmente com os níveis de concentrado. A menor digestibilidade ruminal (13,2 vs 27,5\%) e a maior digestibilidade intestinal da $\mathrm{PB}(86,8$ vs $72,5 \%)$ foram observadas nos bovinos. O pH ruminal nos bubalinos $(6,7)$ foi superior ao dos bovinos $(6,3)$. Nos búfalos, a concentração de amônia ruminal diferiu com os níveis de concentrado, o que não ocorreu com os bovinos. A eficiência microbiana, no entanto, não diferiu entre as espécies e os níveis de concentrado.

Palavras-chave: digestibilidades parcial e total, eficiência microbiana, nitrogênio amoniacal, pH ruminal

\section{Digestibility and ruminal metabolism on bubalines and bovines fed diets with different concentrate levels}

\begin{abstract}
The objective of this trial was to evaluate three different concentrate levels (CL) (23, 43 and $63 \%$ ) on intake, nutrient digestibility, ruminal metabolism, and microbial efficiency in Holstein bovines and Murrah buffaloes (Bubalus bubalis) fed diets containing ground corn and dry cassava by-product as energy sources. Three Holstein bovines and three Murrah buffaloes averaging, respectively, $473 \pm 54 \mathrm{~kg}$ and $400 \pm 33 \mathrm{~kg}$ of body weight (BW), fitted with ruminal and duodenal cannulas were blocked by species and randomly assigned to two replicated $3 \times 3$ Latin squares with a factorial arrangement of treatments. Chromium oxide was used as duodenal and fecal flow marker. Intake of dry matter (DM) was lower on bubalines (1.40\% of BW) than on bovines (1.63\% of BW). The greatest CP intake was of $10.09 \mathrm{~g} / \mathrm{kg} \mathrm{BW}^{0.75}$ for bovines and $8.63 \mathrm{~g} / \mathrm{kg} \mathrm{BW}^{0.75}$ for bubalines with $44.4 \%$ of concentrate in the diet while the highest starch intake was of $32.83 \mathrm{~g} / \mathrm{kg} \mathrm{BW} 0.75$ for bovines and $28.38 \mathrm{~g} / \mathrm{kg} \mathrm{BW} 0.75$ for bubalines with $61.69 \%$ of concentrate in the diet. There were no effects of CL and species on total tract digestibility, ruminal digestibility, and intestinal digestibility of nutrients with the exception of starch and CP. Apparent total tract digestibility of starch was greatest on bovines (95.7 vs. $85.8 \%$ ); ruminal starch digestibility was also greatest on bovines $(87.4 \%$ vs. $81.9 \%$ ) and that increased linearly when the CL was increased in the diet. It was observed lower ruminal digestibility (13.2 vs. $27.5 \%)$ and higher intestinal digestibility $(86.8$ vs. $72.5 \%)$ of $\mathrm{CP}$ on bovines compared to bubalines in this trial. Ruminal $\mathrm{pH}$ averaged 6.7 on bubalines and was greater that than on bovines (6.3). Ruminal ammonia concentration differed across treatments on bubalines but not on bovines whereas microbial efficiency was not affected either by dietary $\mathrm{CL}$ or by species.
\end{abstract}

Key Words: microbial efficiency, partial and total digestibility, ruminal ammonia, ruminal $\mathrm{pH}$ 


\section{Introdução}

Dietas de alta densidade calórica são fundamentais na exploração de animais de alta produção para que possam expressar todo o seu potencial genético. Entre as fontes energéticas usualmente utilizadas, destaca-se o amido, principal fonte de glicose para os ruminantes, gerada a partir dos ácidos orgânicos resultantes da fermentação ruminal. A degradação ruminal do amido favorece a produção de propionato, reduzindo a necessidade de aminoácido para a gliconeogênese no fígado.

$\mathrm{O}$ uso de fontes de amido de alta degradabilidade ruminal pode acarretar maior produção de ácidos graxos voláteis no rúmen, maior digestão total do amido e, conseqüentemente, maior quantidade de EM para o animal (Nocek \& Tamminga, 1991; Huntington, 1997). Contudo, fontes de amido de alta degradabilidade ruminal podem provocar determinados distúrbios ruminais, causando diminuições no consumo, no aporte de EM e na produção animal quando não há controle do $\mathrm{pH}$ ruminal.

As dietas energéticas, ricas em concentrado, podem acarretar mudanças no processo de digestão e no metabolismo dos nutrientes, em decorrência das interações dos alimentos, denominadas efeitos associativos (Coelho da Silva \& Leão, 1979). Em geral, o incremento nos teores de concentrado nas dietas resulta em aumentos na digestibilidade total dos nutrientes, com exceção da digestibilidade da FDN, que diminui ou não é influenciada pelo teor de concentrado (Bürger et al., 2000; Cardoso et al., 2000a; Tibo et al., 2000; Ítavo et al., 2002). Na maioria dos trabalhos para avaliação de níveis crescentes de concentrado na ração, utilizou-se como fonte energética o milho.

Há poucas pesquisas, no entanto, relacionando os níveis de concentrado na ração com fonte de amido de alta degradabilidade ruminal, como trigo, triticale ou raiz de mandioca ou resíduos industriais de farinheira de mandioca. Essas fontes apresentam maior degradabilidade ruminal do amido em comparação ao milho ou ao sorgo, em virtude das características dos grãos e da estrutura dos grânulos de amido (Zeoula \& Caldas Neto, 2001). Visando aumentar a digestão total do amido com fontes como mandioca, a mistura de amido de alta (mandioca) e baixa (milho) degradabilidade ruminal pode constituir alternativa viável para redução dos custos do concentrado.

$\mathrm{O}$ uso de concentrados à base de milho como fonte energética para bovinos já foi extensamente avaliado, porém, com bubalinos são poucos os trabalhos publicados. As diferenças entre bovinos e bubalinos quanto à digestão parecem estar relacionadas à qualidade da dieta. Bubalinos digerem melhor forragens de baixa qualidade, contudo, essas diferenças não são observadas quando fornecidas forragens de boa qualidade (Pradhan et al., 1997).

A distinção entre as espécies bubalina e bovina quanto a dietas de qualidade inferior parece estar relacionada a diversos fatores. Búfalos possuem rúmen com maior atividade celulolítica e melhor aproveitamento dos componentes fibrosos (Tewatia \& Bhatia, 1998), maior número de protozoários ciliados da subfamília Diplodiniinae, responsáveis pela fermentação de carboidratos estruturais (Franzolin \& Franzolin, 2000), maior pH ruminal em decorrência da secreção salivar mais intensa, maior poder tampão da saliva que flui para o rúmen (Sivkova et al., 1997), maior concentração de amônia, refletindo melhor atividade de desaminases intracelular e reciclagem salivar de uréia (Tewatia \& Bhatia, 1998) e manutenção do balanço de nitrogênio positivo em virtude da maior eficiência de utilização do nitrogênio amoniacal pelo uso mais rápido da amônia pelas bactérias ruminais (Mudgal, 1991; Setia et al., 1992; citados por Trufchev et al., 1997).

São poucas as informações sobre os aspectos da digestão de dietas com diferentes teores de concentrado tendo como fonte de amido o resíduo desidratado de fécula de mandioca quando fornecidas a bovinos e raras são as pesquisas com a espécie bubalina. Desse modo, avaliou-se neste estudo o efeito do fornecimento de diferentes níveis de concentrado (23, 43 e $63 \%)$ em dietas contendo como fonte de amido o milho e o resíduo desidratado de fécula de mandioca (de baixa e alta degradabilidade ruminal) sobre o consumo, os coeficientes de digestibilidade ruminal, intestinal e total, a energia, o pH, a concentração de $\mathrm{NH}_{3}$ ruminal e a eficiência de síntese microbiana em bovinos e bubalinos.

\section{Material e Métodos}

Oexperimento foi realizado no setor de Bovinocultura de Corte da Fazenda Experimental de Iguatemi (FEI) no período de maio a agosto de 2003 e as análises químicas, no Laboratório de Análises de Alimentos e Nutrição Animal do Departamento de Zootecnia da Universidade Estadual de Maringá.

Foram utilizados três bovinos (machos castrados) holandeses com $473 \pm 54 \mathrm{~kg}$ de peso corporal e três búfalos (machos castrados) Murrah com $400 \pm 33 \mathrm{~kg}$ de peso corporal, fistulados no rúmen e duodeno. Os animais foram mantidos em baias individuais cobertas, com piso de concreto, providas de comedouro e bebedouro.

A composição percentual e química das três dietas experimentais é demonstrada na Tabela 1. Utilizaram-se farelo de soja, uréia, milho e resíduo desidratado de fécula 
Tabela 1 - Composições percentual e química das dietas experimentais (\% MS)

Table 1 - Ingredient and chemical composition of the experimental diets (\%DM)

\begin{tabular}{|c|c|c|c|}
\hline & \multicolumn{3}{|c|}{$\begin{array}{c}\text { Nível de concentrado (\%) } \\
\text { Concentrate level }(\%)\end{array}$} \\
\hline & 23 & 43 & 63 \\
\hline Farelo de soja & 6,79 & 7,42 & 8,09 \\
\hline \multicolumn{4}{|l|}{ Soybean meal } \\
\hline Milho moído & 6,73 & 16,45 & 25,73 \\
\hline \multicolumn{4}{|l|}{ Ground corn } \\
\hline $\begin{array}{l}\text { Resíduo desidratado de } \\
\text { fécula de mandioca } \\
\text { Dry cassava by-product }\end{array}$ & 6,78 & 16,29 & 25,69 \\
\hline $\begin{array}{l}\text { Silagem de milho } \\
\text { Corn silage }\end{array}$ & 77,00 & 57,00 & 37,00 \\
\hline Uréia & 0,75 & 0,81 & 0,87 \\
\hline \multicolumn{4}{|l|}{ Urea } \\
\hline $\begin{array}{l}\text { Calcário calcítico } \\
\text { Limestone }\end{array}$ & 0,11 & 0,22 & 0,32 \\
\hline \multicolumn{4}{|l|}{ Salt } \\
\hline Bicarbonato & 0,46 & 0,54 & 1,05 \\
\hline \multicolumn{4}{|l|}{ Bicarbonate } \\
\hline MS (MS\%) & 43,90 & 55,38 & 67,90 \\
\hline \multicolumn{4}{|l|}{$D M(D M \%)$} \\
\hline $\mathrm{PB}$ & 12,36 & 12,46 & 12,50 \\
\hline \multicolumn{4}{|l|}{$C P$} \\
\hline $\operatorname{PDR}(\%)^{1}$ & 67,79 & 65,75 & 63,43 \\
\hline \multicolumn{4}{|l|}{$R D P$} \\
\hline Amido & 26,40 & 36,33 & 45,86 \\
\hline \multicolumn{4}{|l|}{ Starch } \\
\hline FDN & 47,32 & 41,24 & 35,05 \\
\hline \multicolumn{4}{|l|}{$N D F$} \\
\hline Cinzas & 4,47 & 3,72 & 3,03 \\
\hline \multicolumn{4}{|l|}{ Ash } \\
\hline $\operatorname{NDT}(\%)^{2}$ & 61,20 & 64,25 & 67,02 \\
\hline$T D N$ & & & \\
\hline
\end{tabular}

de mandioca como alimentos concentrados e silagem de milho como volumoso. Os três níveis de concentrado utilizados nas dietas foram 23, 43 e $63 \%$. As dietas foram balanceadas para serem isoprotéicas, com $12,0 \%$ de PB na MS e apresentarem aproximadamente $33 \%$ de PB na forma de NNP. A dieta foi fornecida duas vezes ao dia, em duas porções iguais, pela manhã (8h) e à tarde (16h), sendo o volumoso e o concentrado misturados no cocho.

Os animais receberam diariamente aproximadamente $50 \mathrm{~g}$ de sal mineral, obtido da mistura 1:1 de sal comum com um suplemento comercial contendo $65,0 \mathrm{~g}$ de $\mathrm{P}, 130,0 \mathrm{~g}$ de $\mathrm{Ca}$ 5,0 g de $\mathrm{Mg}, 13,0 \mathrm{~g}$ de S, $700 \mathrm{mg}$ de Fe, $850 \mathrm{mg}$ de $\mathrm{Cu}, 1.000 \mathrm{mg}$ de Mn, $120 \mathrm{~g}$ de I e $80 \mathrm{~g}$ de Co por quilograma do produto.

Diariamente, foi feita a pesagem das sobras. A oferta de alimentos foi restrita a $2 \%$ do peso corporal para diminuir os efeitos do consumo sobre os coeficientes de digestibilidade.
O experimento foi conduzido em três períodos experimentais, cada um de 21 dias, sendo 14 dias de adaptação dos animais às dietas e 7 dias de coleta. Durante o período de coleta de cada período experimental, foram amostrados os alimentos oferecidos e as sobras, $200 \mathrm{~mL}$ de digesta duodenal e $100 \mathrm{~g}$ de fezes, diretamente no reto dos animais, em intervalos de 12 horas, com incremento de 2 horas entre dias consecutivos, totalizando 12 amostras por animal, representando um período de 24 horas. As amostras foram armazenadas em sacos plásticos, sendo devidamente etiquetadas e congeladas a $-20^{\circ} \mathrm{C}$.

Após o período de coleta, as amostras de alimento, sobras, fezes e digesta duodenal foram secas em estufa a $55^{\circ} \mathrm{C}$ por 96 horas, moídas $(1 \mathrm{~mm})$ individualmente e misturadas em quantidades iguais, com base no peso seco, para formar amostras compostas de fezes e digesta por animal por período. Os animais foram pesados ao final de cada período de adaptação e ao final de cada período de coleta.

O fluido ruminal $(70 \mathrm{~mL})$ foi amostrado via cânula ruminal nos tempos 0 (antes da primeira alimentação), 2, 4, 6 e 8 horas após a alimentação da manhã e o pH foi medido imediatamente após a coleta. O fluido ruminal $(50 \mathrm{~mL})$ foi acidificado com $1 \mathrm{~mL}$ de ácido sulfúrico (1:1) e congelado para quantificação da concentração de $\mathrm{N}-\mathrm{NH}_{3}$.

O fluxo diário de MS no duodeno e nas fezes foi estimado utilizando-se como indicador externo o óxido crômico $\left(\mathrm{Cr}_{2} \mathrm{O}_{3}\right)$. O $\mathrm{Cr}_{2} \mathrm{O}_{3}$ foi embrulhado em papel na quantidade de $5 \mathrm{~g}$ e colocado diretamente no rúmen às $8 \mathrm{e}$ $16 \mathrm{~h}$, totalizando $10 \mathrm{~g} / \mathrm{animal} / \mathrm{dia}$, durante os três períodos de adaptação e coleta (21 dias/período).

As amostras de fezes, digesta duodenal e sobras e os alimentos utilizados nas dietas foram analisados quanto aos teores de MS, MO, PB e EB, conforme descrito por Silva \& Queiroz (2002), FDN, de acordo com Van Soest et al. (1991) e amido, pelo método de Poore et al. (1989), adaptado por Pereira \& Rossi (1995). A dosagem de amônia nas amostras de líquido ruminal foi feita pela técnica de Ferner (1965), modificada por Vieira (1980).

No último dia de cada período, duas horas após a alimentação, o conteúdo ruminal foi amostrado (1,5 kg), misturado a $500 \mathrm{~mL}$ de solução salina $0,9 \%(\mathrm{NaCl})$, homogeneizado em liquidificador e coado com fralda dobrada quatro vezes. $\mathrm{O}$ filtrado foi armazenado a $-20^{\circ} \mathrm{C}$ para ser processado conforme metodologia descrita por Cecava et al. (1990). Para determinação do fluxo duodenal de proteína microbiana, foram utilizadas as bases purinas, quantificadas conforme técnica descrita por Ushida et al. (1985).

Os coeficientes de digestibilidade total e parcial de MS, MO, PB, FDN, EB e amido foram calculados de acordo com 
as fórmulas descritas por Coelho da Silva \& Leão (1979). Os valores de energia digestível foram obtidos considerando o coeficiente de digestibilidade da EB.

Adotou-se um delineamento experimental em dois quadrados latinos $3 \times 3$, com um arranjo fatorial $3 \times 2$, correspondendo a três níveis de concentrado $(23,43$ e $63 \%$ ) e duas espécies (bubalina e bovina), uma em cada quadrado latino, para comparação do consumo, dos coeficientes de digestibilidade dos nutrientes e da eficiência microbiana. As análises estatísticas das variáveis estudadas foram interpretadas utilizando-se o Sistema de Análises Estatísticas e Genéticas (UFV, 1997), por meio de análise de variância. Quando a interação espécie $\times$ tratamento foi significativa, procedeu-se à análise dos efeitos dos tratamentos dentro de cada espécie. Para os valores observados de $\mathrm{pH}$ e N-NH $\mathrm{N}_{3}$ no líquido ruminal, procedeu-se à subdivisão das parcelas experimentais de acordo com os tempos de amostragem.

\section{Resultados e Discussão}

Os consumos de nutrientes e energia das dietas experimentais são descritos na Tabela 2. Não houve interação espécie $\times$ nível de concentrado para os consumos de MS e demais nutrientes avaliados $(\mathrm{P}>0,05)$. Apenas os consumos de $\mathrm{PB}$ e amido diferiram $(\mathrm{P}<0,05)$ entre os níveis de concentrado. Os consumos de MS, energia, MO, PB, FDN e amido, no entanto, foram influenciados $(\mathrm{P}<0,05)$ pela espécie.

O consumo médio de MS nos bubalinos (1,40\% do peso corporal) foi inferior $(\mathrm{P}<0,05)$ ao dos bovinos $(1,63 \%$ do peso corporal). Diferiu ainda entre as espécies $(\mathrm{P}<0,05)$ tanto em $\mathrm{kg} / \mathrm{dia}$ quanto em $\mathrm{g} / \mathrm{kg} \mathrm{PC} \mathrm{PC}^{0,75}$, observando-se os maiores valores nos bovinos (7,78 vs $5,63 \mathrm{~kg} / \mathrm{dia}$ e $76,07 \mathrm{vs}$ $62,61 \mathrm{~g} / \mathrm{kg} \mathrm{PC}^{0,75}$ para bovinos e bubalinos, respectivamente). O consumo de $5,63 \mathrm{~kg}$ de MS/dia nos búfalos foi inferior aos valores recomendados por Kearl (2003), de

Tabela 2 - Consumo de nutrientes em bovinos e bubalinos alimentados com dietas formuladas com diferentes níveis de concentrado Table 2 - Nutrient intakes of diets with increasing levels of concentrate fed to bovines and bubalines

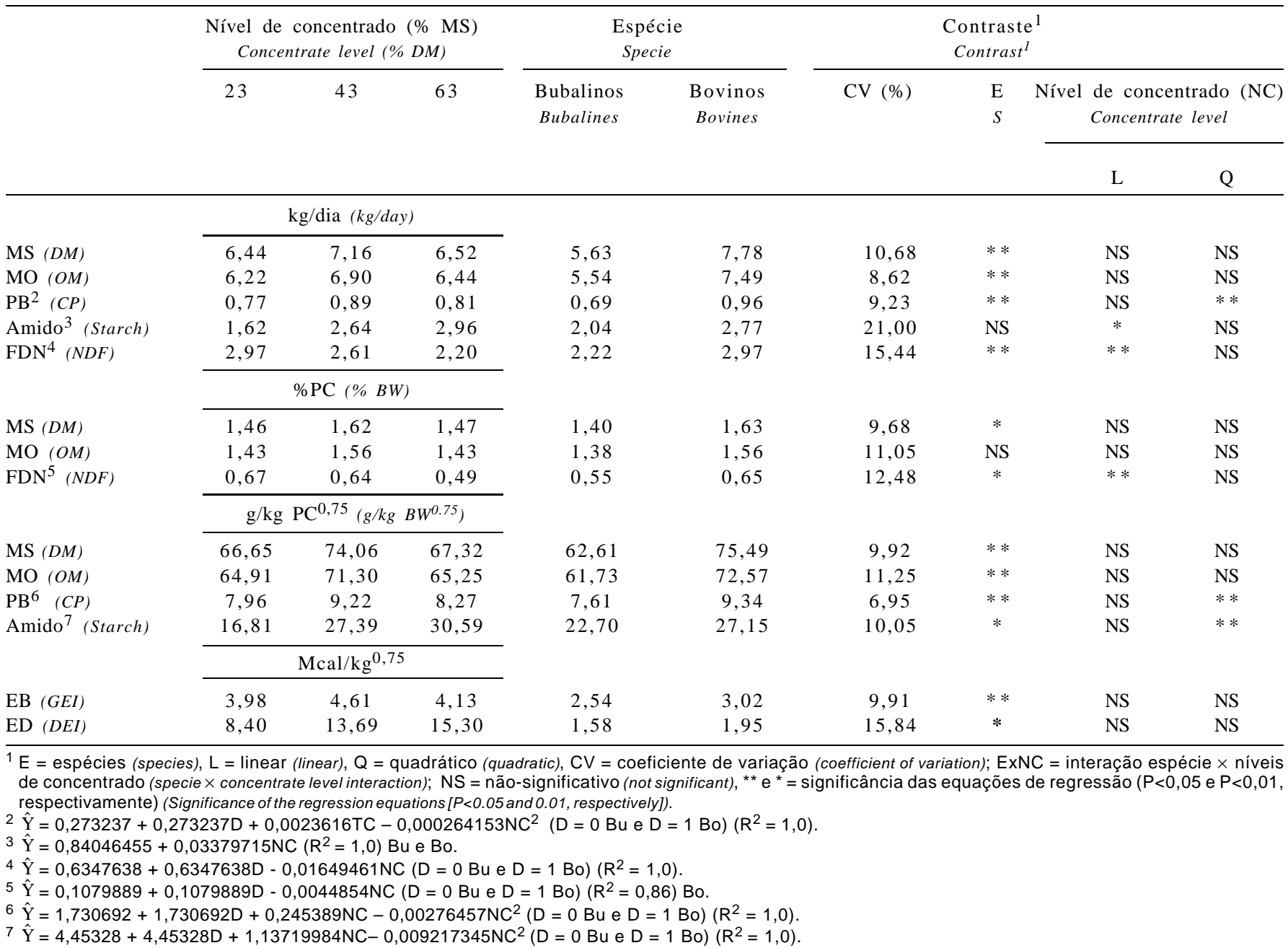


$7,0 \mathrm{~kg}$ MS/dia para búfalos com $400 \mathrm{~kg}$ em mantença e para os bovinos, todavia, foi próximo ao recomendado pelo NRC (1988), de 7,9 kg de MS para animais em mantença com $500 \mathrm{~kg}$ de peso corporal.

O concentrado utilizado no experimento foi formulado para conter como fonte energética partes iguais de milho (fonte de amido de baixa degradabilidade ruminal) e resíduo desidratado de fécula de mandioca (fonte de amido de alta degradabilidade ruminal) (Zeoula et al., 1999). É provável que a inclusão do resíduo desidratado de fécula de mandioca tenha contribuído para o baixo consumo de MS em ambas as espécies, visto que esse alimento possui taxa de degradação ruminal mais rápida em comparação ao milho, teor de MS superior a 90\%, baixo teor de EE e textura de pó, o que lhe confere um aspecto pulverulento. Segundo Hill (1970), citado por Peixoto \& Warner (1993) e Van Soest (1994), alimentos muito secos provocam considerável fluxo de saliva aquosa com muito pouca mucina, o que dificulta a mastigação e a deglutição.

Em geral, a substituição do milho por resíduos de mandioca tem provocado redução no consumo, como observado por Marques et al. (2000) em novilhas mestiças em confinamento. Jorge et al. (2002) avaliaram o efeito do uso de varredura de mandioca $(0 ; 25 ; 50 ; 75$ e $100 \%)$ em substituição ao milho em dietas para bezerros holandeses com relação volumoso:concentrado de 20:80\% e observaram redução linear no consumo médio total de MS conforme aumentaram os níveis de farinha de varredura de mandioca. Do mesmo modo, Dian (2004) avaliou diferentes níveis de substituição do milho por resíduo desidratado de fécula de mandioca em bovinos terminados em confinamento e observou redução linear no consumo com o aumento dos níveis desse subproduto na dieta.

O menor consumo de MS pelos bubalinos em relação aos bovinos refletiu em menor consumo de nutrientes e energia. O consumo máximo de $\mathrm{PB}$ em $\mathrm{kg} / \mathrm{dia}$ foi de 1,03 para os bovinos e de 0,75 para os bubalinos alimentados com a dieta contendo $44,7 \%$ de concentrado. O consumo em g/ $/ \mathrm{kg} \mathrm{PC}^{0,75}$ foi de 10,09 para bovinos e de 8,36 para búfalos alimentados com 44,3\% de concentrado. O consumo máximo de PB obtido nos bovinos alimentados com 44,7\% de concentrado na dieta foi superior ao recomendado pelo NRC (1988), de $789 \mathrm{~g} / \mathrm{dia}$, para bovinos holandeses não-castrados com $500 \mathrm{~kg}$ de peso corporal em mantença. De fato, os bovinos apresentaram, durante todo o período experimental (63 dias), variação média de $+0,2 \mathrm{~kg}$ PC/dia no ganho de peso.

O consumo máximo de PB nos búfalos obtido com a dieta formulada com $44,7 \%$ de concentrado foi semelhante ao recomendado por Kearl (2003), de $740 \mathrm{~g} \mathrm{PB/dia} \mathrm{para}$ búfalos com $400 \mathrm{~kg}$ de peso corporal e ganho de $500 \mathrm{~g} / \mathrm{dia}$.
Em todos os níveis de concentrado, o consumo de PB manteve-se acima das exigências de mantença descritas por Kearl (2003), de 469 g/dia.

Segundo Zicarelli (2001), em condições de déficit protéico, os búfalos podem apresentar exigências de proteína de mantença menores que as de bovinos, em virtude de sua eficiente reciclagem de uréia. Entretanto, quando alimentados com excesso de proteína, apresentam maior disponibilidade de cetoácidos gliconeogênicos, que normalmente derivam do metabolismo protéico e favorecem a síntese de glicose.

O ganho de peso nos búfalos apresentou variação em todo o período experimental (em torno de $-0,32 \mathrm{~kg}$ de peso corporal/dia). Considerando as recomendações de Kearl (2003), provavelmente a perda de peso não foi ocasionada pelo consumo de proteína, mas pelos baixos consumos de energia (Tabela 2).

$\mathrm{O}$ consumo de amido em $\mathrm{kg} / \mathrm{dia}$ não diferiu $(\mathrm{P}>0,05)$ entre as espécies, porém, aumentou linearmente com os níveis de concentrado. Entretanto, quando expresso em $\mathrm{g} / \mathrm{kg} \mathrm{PC}^{0,75}$, sofreu efeito quadrático, com valores máximos de $32,83 \mathrm{~g} / \mathrm{kg} \mathrm{PC}^{0,75}$ (bovinos) e $28,38 \mathrm{~g} / \mathrm{kg} \mathrm{PC}^{0,75}$ (búfalos) para o nível de $61,6 \%$ de concentrado. O menor consumo de amido pelos búfalos foi conseqüência do menor consumo de MS e da menor aceitabilidade das dietas, pois, visualmente, observou-se maior quantidade de concentrado nas sobras das dietas consumidas por esses animais.

$\mathrm{O}$ consumo de FDN expresso em $\mathrm{kg} / \mathrm{dia}$ e em \% PC diferiu entre as espécies $(P<0,05)$, verificando-se consumos médios de 2,97 kg/dia e 0,65\% PC para bovinos e de 2,22 kg/ dia e $0,55 \%$ PC para os búfalos. Houve redução linear $(\mathrm{P}<0,01)$ para o consumo de FDN, em ambas as espécies, conforme aumentaram os níveis de concentrado na dieta. Esses dados corroboram os relatos de Cardoso et al. (2000a), que alimentaram novilhos mestiços F1 Limousin x Nelore com dietas com diferentes teores de concentrado e observaram redução linear no consumo de FDN com o aumento dos níveis de concentrado. O consumo de FDN em \% PC foi inferior ao mínimo recomendado pelo NRC (2001), de 1,1\% para dietas com forragens em tamanho de partícula ideal e grão de milho como principal fonte de amido.

Apesar do aumento no consumo de amido e da redução no consumo da FDN com o aumento nos níveis de concentrado das dietas, em ambas as espécies, esses aumentos não refletiram em aumentos no consumo e na concentração de energia das rações. Possivelmente, o baixo consumo de MS e MO e principalmente o fato de os teores de concentrado não terem influenciado as digestibilidades total, ruminal e intestinal da MS e da MO (Tabela 3) justifiquem estes resultados. 
Os coeficientes de digestibilidade, as digestões ruminal (DR) e intestinal (DI) da MS (\% do total digerido) e dos demais nutrientes, a EB e a eficiência de síntese microbiana são descritos na Tabela 3.

Não houve interação nível de concentrado $\times$ espécie para os coeficientes de digestibilidade de MS, MO, PB, amido, FDN e EB. Do mesmo modo, não foi constatado efeito dos níveis de concentrado sobre os coeficientes de digestibilidade dos nutrientes. Entre espécies, apenas os coeficientes de digestibilidade do amido diferiram.

Os coeficientes de digestibilidade da MS e MO nos búfalos foram de 59,8 e 63,2\% e, nos bovinos, de 64,5 e $67,2 \%$, respectivamente. Valadares Filho et al. (1990), ao fornecerem dietas com $44 \%$ de concentrado para novilhos holandeses e Nelore e búfalos, também não observaram diferenças significativas nas digestibilidades totais da MS e MO. Os autores atribuíram essa ausência de diferenças entre os grupos genéticos ao fato de o consumo ter sido restrito a $56 \mathrm{~g} \mathrm{MS} / \mathrm{kg} \mathrm{PC}^{0,75}$. Todavia, neste trabalho, o consumo de MS para os bovinos foi de 76,07 $\mathrm{g} / \mathrm{kg} \mathrm{PC} \mathrm{PC}^{0,75}$, superior $(\mathrm{P}<0,05)$ ao dos búfalos $\left(62,61 \mathrm{~g} / \mathrm{kg} \mathrm{PC}^{0,75}\right)$.

De modo geral, o menor consumo de MS resulta em menor taxa de passagem da digesta em maior digestibilidade da MS (Van Soest, 1994), entretanto, nos búfalos com menor consumo, isso não ocorreu. Segundo Bartocci et al. (1997), em virtude da menor ingestão, búfalos retêm por

Tabela 3 - Digestibilidade (\% do total digerido) dos nutrientes e eficiência de síntese microbiana (g N-Mic/kg MOADR) em bovinos e bubalinos alimentados com dietas formuladas com diferentes níveis de concentrado

Table 3 - Apparent total tract nutrient digestibility and efficiency of microbial protein synthesis on diets with increasing levels of concentrate fed to bovines and bubalines

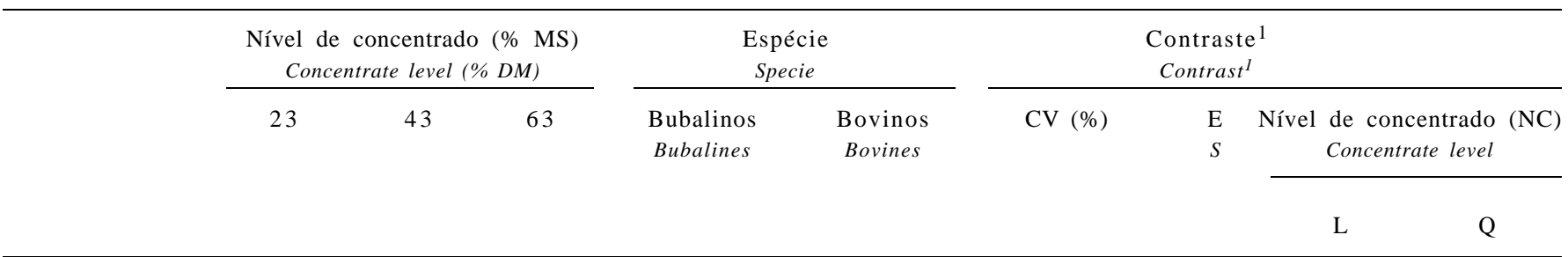

\begin{tabular}{|c|c|c|c|c|c|c|c|c|c|}
\hline \multirow[b]{2}{*}{$\operatorname{MS}(D M)$} & \multicolumn{3}{|c|}{$\begin{array}{l}\text { Digestibilidade total } \\
\text { Total tract digestibility }\end{array}$} & \multirow[b]{2}{*}{59,8} & \multirow[b]{2}{*}{64,5} & \multirow[b]{2}{*}{8,37} & \multirow[b]{2}{*}{ NS } & \multirow[b]{2}{*}{ NS } & \multirow[b]{2}{*}{ NS } \\
\hline & 60,8 & 62,5 & 63,3 & & & & & & \\
\hline MO (OM) & 64,6 & 67,3 & 66,0 & 64,4 & 67,5 & 10,35 & NS & NS & NS \\
\hline $\mathrm{PB}(C P)$ & 59,6 & 58,4 & 57,1 & 58,7 & 58,0 & 5,48 & NS & NS & NS \\
\hline Amido (Starch) & 90,9 & 89,7 & 91,7 & 85,8 & 95,7 & 2,28 & $*$ & NS & NS \\
\hline FDN $(N D F)$ & 53,9 & 53,3 & 49,7 & 53,3 & 51,2 & 19,80 & NS & NS & NS \\
\hline \multirow[t]{2}{*}{$\mathrm{EB}(G E)$} & 61,8 & 64,1 & 64,0 & 62,0 & 64,5 & 10,21 & NS & NS & NS \\
\hline & \multicolumn{3}{|c|}{$\begin{array}{l}\text { Digestibilidade ruminal } \\
\text { Ruminal digestibility }\end{array}$} & & & & & & \\
\hline $\operatorname{MS}(D M)$ & 55,4 & 56,2 & 55,4 & 56,8 & 54,4 & 13,74 & NS & NS & NS \\
\hline $\mathrm{MO}(O M)$ & 62,0 & 65,3 & 62,7 & 64,7 & 61,9 & 8,72 & NS & NS & NS \\
\hline $\mathrm{PB}(C P)$ & 20,3 & 24,9 & 16,0 & 27,5 & 13,2 & 48,58 & $* *$ & NS & NS \\
\hline Amido $^{2}$ (Starch) & 81,9 & 85,6 & 86,5 & 81,9 & 87,4 & 3,87 & $* *$ & $* *$ & NS \\
\hline FDN $(N D F)$ & 90,6 & 85,2 & 77,9 & 83,2 & 85,9 & 22,44 & NS & NS & NS \\
\hline \multirow[t]{2}{*}{$\mathrm{EB}(G E)$} & 60,5 & 67,6 & 68,0 & 68,0 & 62,7 & 14,86 & NS & NS & NS \\
\hline & \multicolumn{3}{|c|}{$\begin{array}{l}\text { Digestibilidade intestinal } \\
\text { Intestinal digestibility }\end{array}$} & & & & & & \\
\hline $\operatorname{MS}(D M)$ & 44,7 & 43,9 & 44,7 & 43,2 & 45,6 & 10,81 & NS & NS & NS \\
\hline MO (OM) & 38,0 & 34,7 & 37,4 & 35,3 & 38,1 & 15,04 & NS & NS & NS \\
\hline $\mathrm{PB}(C P)$ & 79,8 & 75,2 & 84,1 & 72,5 & 86,8 & 12,42 & $* *$ & NS & NS \\
\hline Amido $^{3}$ (Starch) & 18,1 & 14,4 & 13,5 & 18,1 & 12,6 & 21,35 & $* *$ & $* *$ & NS \\
\hline FDN $(N D F)$ & 9,5 & 14,8 & 22,1 & 16,8 & 14,1 & 122,0 & NS & NS & NS \\
\hline \multirow[t]{2}{*}{$\mathrm{EB}(G E)$} & 39,5 & 32,5 & 32,0 & \multirow[t]{2}{*}{32,0} & 37,3 & 28,00 & NS & NS & NS \\
\hline & \multicolumn{3}{|c|}{$\begin{array}{c}\text { Síntese microbiana } \\
\text { Microbial protein synthesis }\end{array}$} & & & & & & \\
\hline $\operatorname{MOADR}^{4}(O M A D R)$ & 13,0 & 16,8 & 13,0 & 10,5 & 18,0 & 52,76 & NS & NS & NS \\
\hline
\end{tabular}


mais tempo a digesta no rúmen-retículo. Entretanto, o tempo de retenção no trato digestivo total é menor, como resultado do menor tamanho do intestino, que reduz o tempo de permanência da digesta. De fato, a DR da MS foi semelhante em ambas as espécies e a DI da MS, quando expressa em relação à quantidade que chegou nos intestinos, foi inferior para os búfalos em relação aos bovinos ( 39,1 vs $44,8 \%)$. Desse modo, os resultados encontrados para o consumo e o coeficiente de digestibilidade da MS, em parte, parecem ser justificados. Maior tempo de permanência da digesta nos búfalos foi observado por Terramoccia et al. (2000), que encontraram diferença para taxas de passagem de sólidos de $0,0246 \mathrm{~h}^{-1}$ em búfalos e de $0,0298 \mathrm{~h}^{-1}$ em bovinos.

Os coeficientes de digestibilidade de PB, FDN e EB não foram influenciados pela espécie nem pelo nível de concentrado, com valores médios de 58,7; 53,3 e 62,0\%, respectivamente, para os búfalos e de 58,0;51,2 e $64,5 \%$ para os bovinos (Tabela 3 ).

Semelhantemente aos resultados observados para a digestibilidade da PB, Rodrigues et al. (2001) não observaram diferença na digestibilidade total da $\mathrm{PB}$ entre búfalos $(46,2 \%)$ e bovinos $(43,3 \%)$ alimentados com dietas com relação volumoso:concentrado de 40:60. O volumoso foi composto de silagem com $70 \%$ de capim-elefante e $30 \%$ de sorgo e concentrado com milho desintegrado com palha e sabugo, farelo de algodão, milho moído e cama de frango. Entretanto, pequena vantagem na digestibilidade da $\mathrm{PB}$ em búfalos, quando comparados aos bovinos tem sido relatada, assumindo-se que há tendência de os búfalos perderem menos $\mathrm{N}$ pela urina e fezes e aproveitarem melhor o $\mathrm{N}$ dos alimentos (Ezequiel, 1987), por apresentarem maior capacidade de reciclagem de $\mathrm{N}$ (Abdullah et al., 1992).

Souza et al. (2000) também não observaram diferença no coeficiente de digestibilidade da FDN entre bovinos $(54,0 \%)$ e bubalinos $(55,9 \%)$ alimentados com dietas formuladas com níveis crescentes de FDN. Segundo Kawashima (2004), os búfalos, em comparação aos Bos taurus, são mais eficientes para digerir a fibra em dietas de qualidade inferior. Esses autores verificaram que, para os búfalos, não houve diferença para a digestibilidade da FDN quando alimentados com dietas à base de feno de gramínea (Brachiaria ruziziensis) com 2,5\% PB ou quando suplementados com farelo de soja. Entretanto, em bovinos Brahman, houve aumento da digestibilidade da FDN com a suplementação do farelo de soja. Portanto, diferenças na digestão da fibra entre bovinos e bubalinos estariam relacionadas a dietas de baixa qualidade, o que não ocorreu neste trabalho, visto que as dietas continham concentrado e silagem de milho (30,4\% de MS e 7,8\% de PB) como volumoso e foram balanceadas para serem isoprotéicas
(12\% de PB) e com concentração energética de 61,20 a $67,02 \%$ de NDT.

Houve efeito da espécie $(\mathrm{P}<0,01)$ sobre o coeficiente de digestibilidade do amido, porém, o mesmo não foi observado para o nível de concentrado, sendo que os bovinos apresentaram coeficiente de digestibilidade médio $(95,7 \%)$ superior ao dos búfalos $(85,8 \%)$, apesar do menor consumo de MS e de amido pelos búfalos.

Beleze (2005) observou maior coeficiente de digestibilidade do amido em bovinos $(88,4 \mathrm{e} 84,0 \%)$ quando comparados a búfalos $(86,0$ e $81,2 \%)$ alimentados com dietas com relação volumoso:concentrado 50:50 e 80:20, respectivamente. Entretanto, Zeoula et al. (1997), em estudo com taurinos, zebuínos e bubalinos alimentados com três fontes de amido (milho, sorgo e raspa de mandioca), verificaram maior digestibilidade dos carboidratos totais disponíveis (amido e carboidratos solúveis) nos búfalos $(94,40 \%)$ e menor nos taurinos $(93,40 \%)$. No entanto, os autores afirmam que, do ponto de vista biológico, estas diferenças são pequenas.

Não houve interação de nível de concentrado $\times$ espécie para as digestibilidades ruminal e intestinal dos nutrientes (P>0,05) e, à exceção das digestibilidades ruminal e intestinal da $\mathrm{PB}$ e do $\mathrm{AM}(\mathrm{P}<0,05)$, não houve efeito do nível de concentrado e da espécie sobre as digestibilidades ruminal e intestinal dos demais nutrientes $(\mathrm{P}>0,05)$ (Tabela 3 ).

Em ambas as espécies, parte da MS total (55,6\%) e da MO (63,3\%) foi digerida no rúmen. Esses valores são inferiores aos valores médios observados por Valadares Filho et al. (1990), de 66,3\% de MS e 72,1\% de MO, ao testarem dietas purificadas e semipurificadas de celulose de madeira em novilhos holandeses, Nelores e búfalos, que não diferiram entre si.

Observou-se diferença entre as espécies para a DR da $\mathrm{PB}$, com maiores valores para os bubalinos $(27,5 \%)$ que para os bovinos $(13,2 \%)$. Estes resultados indicaram maior digestão da proteína no rúmen para os búfalos e conseqüente desaparecimento do nitrogênio, o que pode significar maior absorção de amônia pela parede do rúmen ou menor fixação de $\mathrm{N}$ na forma de $\mathrm{N}$ microbiano (10,5 g N-microbiano/kg MOADR para os búfalos e 18,0 g N-mic/kg MOADR para os bovinos). Provavelmente, esses resultados são reflexos da menor digestibilidade ruminal do amido e do menor consumo de energia digestível nos bubalinos (Tabela 3). Nos bovinos, os resultados de DR da PB também foram positivos, diferentes dos resultados próximos de zero ou negativos observados na literatura (Cardoso et al., 2000a; Dias et al., 2000).

Segundo Bartocci et al. (1997), uma das características próprias dos microrganismos ruminais dos bubalinos, em comparação aos bovinos, é a capacidade de atacar e fermentar 
a proteína no rúmen muito mais rapidamente. Além disso, o alimento permanece mais tempo no rúmen e menos nos intestinos, fazendo com que pouca proteína com potencial de degradação ruminal passe pelo rúmen sem sofrer degradação e que sejam utilizáveis diretamente em nível intestinal (Di Lella et al., 1995).

A digestibilidade ruminal do amido diferiu $(\mathrm{P}<0,05)$ entre as espécies, sendo observados valores médios de $87,4 \%$ para os bovinos e de $81,9 \%$ para os bubalinos. Entretanto, os resultados observados na literatura são controversos, pois, segundo Valadares Filho et al. (1990), búfalos apresentaram maior digestão ruminal para os carboidratos solúveis em relação a bovinos holandeses. Esses autores observaram digestão ruminal superior à obtida neste trabalho ( $92,7 \%$ do total digerido) e ressaltaram que a dieta era purificada, ou seja, não continha milho, e sim amido do milho. Zeoula et al. (1997) também verificaram maior digestibilidade ruminal de carboidratos totais disponíveis (amido como principal componente) nos búfalos (89,3\%) em comparação aos bovinos holandeses $(78,6 \%)$. As digestibilidades ruminais foram maiores para dietas contendo raspa de mandioca $(93,1 \%)$ que para aquelas com milho (72,0\%). Entretanto, Beleze (2005) observou maior digestibilidade ruminal do amido em bovinos em relação aos bubalinos alimentados com rações com relação volumoso:concentrado 50:50.

Quanto aos níveis de concentrado, a digestibilidade ruminal do amido aumentou linearmente com aumento dos níveis de concentrado. O inverso, no entanto, foi observado para a digestibilidade intestinal do amido.

A digestibilidade ruminal da FDN não diferiu entre as espécies, sendo obtidos valores médios de $42,6 \%$ para os búfalos e de $44,2 \%$ para os bovinos. Esses resultados podem ter sido ocasionados pelo fato de que a principal fonte de FDN das dietas foi proveniente da silagem de milho, um volumoso de melhor qualidade. A distinção no aproveitamento da fração fibrosa entre búfalos e bovinos está relacionada à qualidade da fibra, à composição da microbiota ruminal e ao tempo de retenção da digesta no rúmen (Bartocci et al., 1997; Franzolin \& Franzolin, 2000; Terramoccia et al., 2000; Kawashima, 2004).

A digestibilidade ruminal da $\mathrm{EB}(\mathrm{P}>0,05)$ não foi afetada pela espécie ou pelo nível de concentrado da dieta $(68,0 \%$ para os búfalos e $62,7 \%$ para os bovinos). Ressalta-se que esses valores médios foram próximos aos observados para a digestibilidade ruminal da MO $(64,7 \%$ para os búfalos e $62,0 \%$ para os bovinos), haja vista a grande similaridade entre a MO digerida no rúmen e a energia digestível (ED) no rúmen.

Não houve efeito da espécie nem do nível de concentrado sobre a digestão intestinal da MS, obtendo-se média de 44,5\% (intestino delgado + intestino grosso) para os bovinos e de $41,4 \%$ nos búfalos. Por outro lado, quando a digestibilidade intestinal foi expressa em relação à quantidade que chegou aos intestinos, os búfalos apresentaram menor $(\mathrm{P}<0,05)$ digestibilidade intestinal da MS $(39,1)$ em comparação aos bovinos $(44,8 \%)$. Essas observações corroboram as afirmativas de Angulo et al. (2005) de que búfalos apresentam maior peso do rúmen-retículo $(7,38 \mathrm{~kg})$ e menor tamanho do intestino delgado (26,5 m) em relação a taurinos $(5,72 \mathrm{~kg}$ e 39,5 $\mathrm{m}$, respectivamente).

A digestibilidade intestinal da $\mathrm{PB}$ foi afetada apenas pela espécie, obtendo-se maior valor $(\mathrm{P}<0,05)$ para os bovinos $(86,8 \%)$ em comparação aos búfalos $(72,5 \%)$. O menor valor para digetibilidade intestinal da PB pode ser decorrente da maior digestão ruminal dos búfalos. De forma análoga, admitese maior participação do intestino delgado na digestão da PB nos bovinos, em decorrência da menor participação ruminal.

Nos búfalos, a média $(18,1 \%)$ da digestibilidade intestinal do amido foi maior $(\mathrm{P}<0,05)$ que nos bovinos $(12,6 \%)$, provavelmente em virtude da menor digestão ruminal nesses animais. Entretanto, quando expressa em relação à quantidade de nutriente que chega aos intestinos, a digestão do amido nos intestinos nos búfalos foi menor que nos bovinos $(52,2 \%$ vs $70,8 \%)$ e similar à digestão de proteína $(51,0 \%$ vs $54,5 \%)$, o que resultou em maior aproveitamento intestinal do amido e da proteína nos bovinos.

Não houve diferença na eficiência microbiana para a interação nível de concentrado $\times$ espécie, com médias de 10,5 g N-microbiano/kg para búfalos e de 18,0 g N-mic/kg MOADR para os bovinos. Esses valores foram inferiores ao considerado aceitável pelo ARC (1984), de 32,0 gN-Mic/kg MOADR. Variabilidade na eficiência microbiana de 16,01 a 57,2 g N-mic/kg MOADR tem sido observada na literatura (Berchielli et al., 1995; Guimarães et al., 2001; Fregadolli et al., 2001; Zeoula et al., 2002) e foi ocasionada pela inadequada quantidade (deficiência ou excesso) de proteína degradável no rúmen e/ou de energia para o crescimento microbiano.

Não houve interação espécie $\times$ nível de concentrado $(\mathrm{P}>0,05)$ para o $\mathrm{pH}$ do líquido ruminal, porém, foi observada diferença $(\mathrm{P}<0,05)$ nos tempos de coleta $0,2,4,6$ e 8 horas após a alimentação da manhã para os nível de concentrado na dieta (Figura 1). Verificou-se redução linear do pH no rúmen com o aumento do teor de concentrado na dieta ( $\hat{\mathrm{Y}} \mathrm{pH}=0,37192+0,37192 \mathrm{D}-0,0027 \mathrm{NC}\left(\mathrm{R}^{2}=0,68\right)$, em que $\mathrm{D}=1$ búfalos e $\mathrm{D}=0$ bovinos e $\mathrm{NC}=$ nível de concentrado). Do mesmo modo, reduções no $\mathrm{pH}$ do líquido ruminal foram observadas na literatura em estudos com dietas contendo diferentes níveis de concentrado para bovinos (Ladeira et al., 1999; Dias et al., 2000). Entretanto, os valores de pH, considerando os diferentes níveis de concentrado, 
mantiveram-se acima de 6,0 e não interferiram na digestão ruminal da fibra, como observado nos coeficientes de digestibilidade ruminal e total da FDN, que foram semelhantes (Tabela 3).

Foi constatada interação espécie $\times$ tempo $(\mathrm{P}<0,01)$ sobre o $\mathrm{pH}$ do líquido ruminal (Figura 1). Em ambas as espécies, foi observado efeito quadrático, com valores máximos de $\mathrm{pH}$ de 6,87 para búfalos e de 6,65 para bovinos no tempo zero hora (antes da alimentação). O valor mínimo estimado de $\mathrm{pH}$ do líquido ruminal para os búfalos foi de 6,40 às 4,78 horas e, para os bovinos, de 6,30 às 4,40 horas após a alimentação.

De modo similar, Souza et al. (2000) verificaram maior $\mathrm{pH}$ ruminal em bubalinos em comparação a bovinos. De acordo com Sivkova et al. (1997), em búfalos e bovinos alimentados com rações com 55:45 concentrado:volumoso, o pH diferiu entre ambas as espécies 2 horas e 30 minutos depois da alimentação, sendo maior nos búfalos que nos bovinos. Segundo esses autores, bubalinos apresentam secreção salivar mais intensa e maior poder tampão da saliva que fluiu para o rúmen.

Os maiores valores de $\mathrm{pH}$ ruminal para os búfalos e a menor variação ao longo dos horários de coleta, ao contrário dos bovinos, podem ser explicados pelo comportamento alimentar durante o período experimental, visto que o consumo pelos bubalinos ocorreu de forma mais gradativa ao longo do dia, o que fez com que não apresentassem quedas bruscas de $\mathrm{pH}$.

Verificaram-se interações espécie $\times$ tempo de coleta de líquido ruminal $(0,2,4,6$ e 8 horas após a alimentação da manhã $)(\mathrm{P}<0,05)$ e espécies $\times$ nível de concentrado $(\mathrm{P}<0,01)$ para a concentração de nitrogênio amoniacal $\left(\mathrm{N}-\mathrm{NH}_{3}\right)$. As concentrações de $\mathrm{N}-\mathrm{NH}_{3}$ do líquido ruminal na espécie bubalina (Figura 1) se comportaram de forma quadrática em virtude dos níveis de concentrado e do tempo após a primeira alimentação, obtendo-se a seguinte equação ajustada, $\mathrm{NH}_{3} \hat{\mathrm{Y}}=19,3804-15,0109 \mathrm{NC}+4,51155 \mathrm{NC}^{2}+$ $2,01831 T-0,29491 T^{2}\left(R^{2}=0,42\right)$. Nos bovinos (Figura 1), observou-se efeito cúbico somente em relação ao tempo, $\mathrm{NH}_{3} \hat{\mathrm{Y}}=7,17543+13,2688 \mathrm{~T}-4,1671 \mathrm{~T}^{2}+0,310967 \mathrm{~T}^{3}$ $\left(\mathrm{R}^{2}=058\right)$, em que $\mathrm{T}=$ tempo de coleta.

O efeito do tempo de coleta sobre a concentração de amônia foi significativo $(\mathrm{P}<0,01)$, característica comum em ruminantes alimentados de forma intermitente (Mehres et al., 1977). A máxima concentração de $\mathrm{N}-\mathrm{NH}_{3}$ nos bubalinos foi obtida às 3,42 horas após o fornecimento das dietas, sendo de 19,62 para $23 \%$, de 17,20 para $43 \%$ e de $15,16 \mathrm{mg}$ $\mathrm{N}-\mathrm{NH}_{3} / 100 \mathrm{~mL}$ para $63 \%$ de concentrado. Apesar das diferenças na concentração de $\mathrm{N}-\mathrm{NH}_{3}$ entre os diferentes níveis de concentrado, as perdas de amônia pela parede
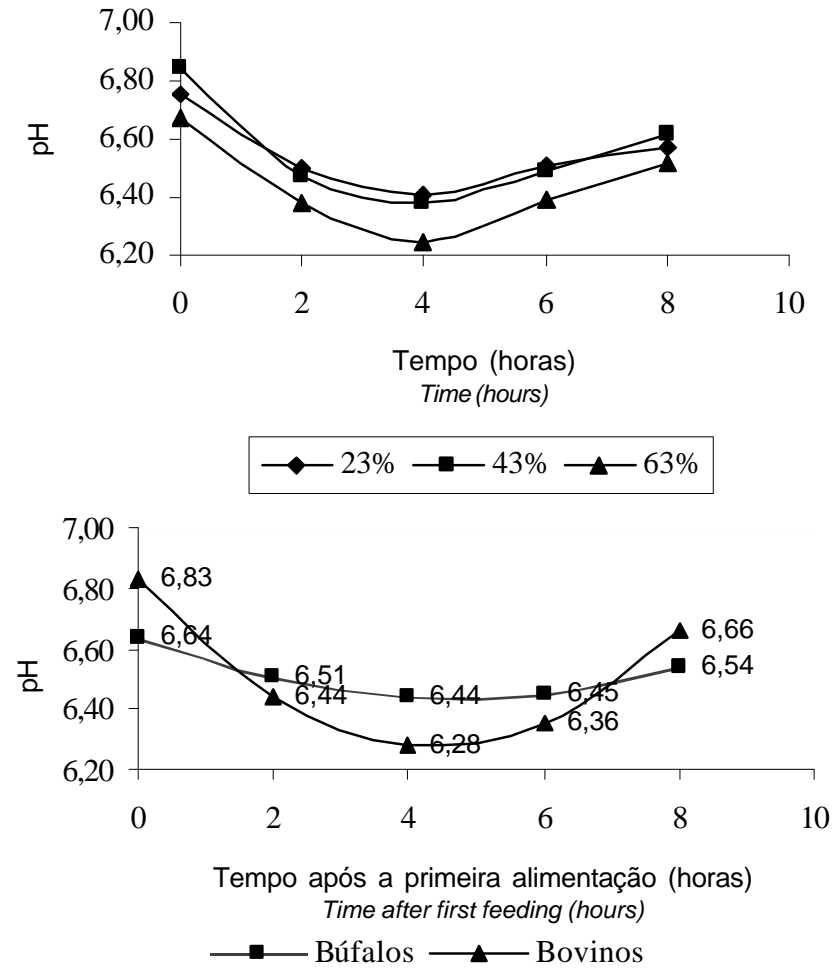

$\longrightarrow \hat{\mathrm{Y}} \mathrm{pH}=6,64-0,085 \mathrm{~T}+0,009 \mathrm{~T}^{2}\left(\mathrm{R}^{2}=0,68\right)$
$\longrightarrow \hat{\mathrm{Y}} \mathrm{pH}=6,83-0,253 \mathrm{~T}+0,029 \mathrm{~T}^{2}\left(\mathrm{R}^{2}=0,98\right)$
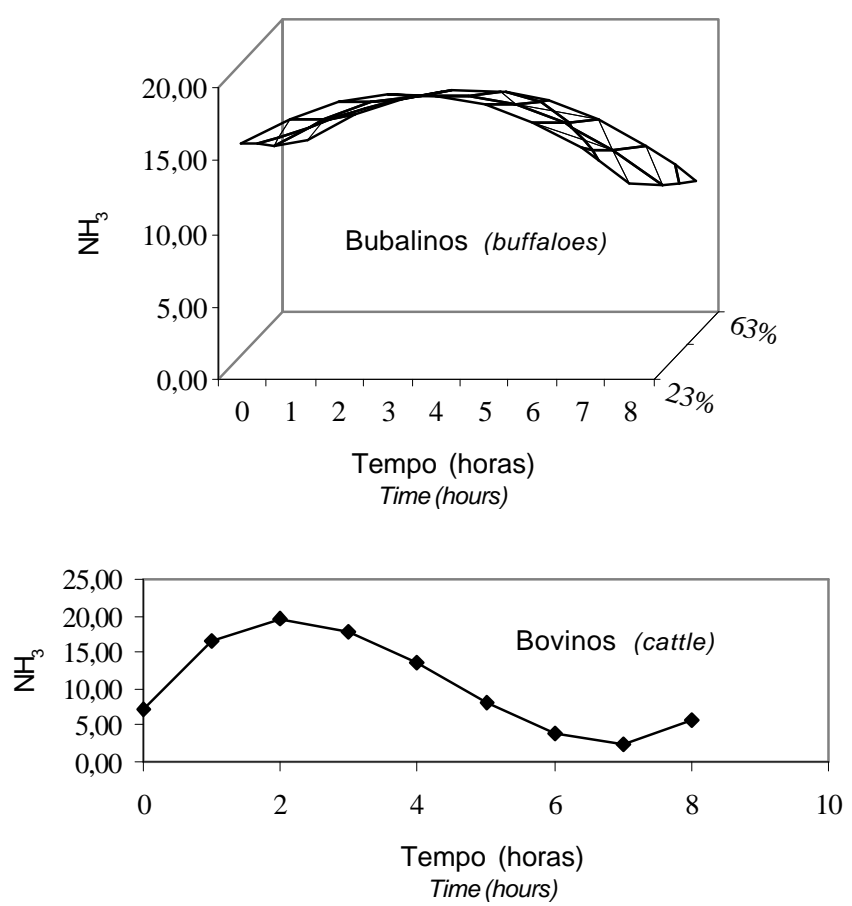

Figura 1 - Concentração de nitrogênio amoniacal (N-NH , $\mathrm{mg} / 100 \mathrm{~mL}$ do líquido ruminal) e $\mathrm{pH}$ em diferentes tempos após a alimentação em bovinos e bubalinos alimentados com três níveis de concentrado na dieta.

Figure 1 - Diurnal variation of ruminal ammonia nitrogen $\left(\mathrm{N}-\mathrm{NH}_{3}\right.$; $\mathrm{mg} / 100 \mathrm{~mL}$ of ruminal fluid) and $\mathrm{pH}$ in cattle fed diets with increasing levels of concentrate. 
ruminal foram semelhantes, como observado na digestibilidade ruminal da PB (27\% do total digerido) e na eficiência microbiana, que não diferiu. Por outro lado, a menor concentração de $\mathrm{N}-\mathrm{NH}_{3}$ nos maiores níveis de concentrado provavelmente resultou do consumo de PB, que, para os búfalos, foi quadrático, em razão dos níveis de concentrado. À exceção da dieta com $23 \%$ de concentrado, nos demais níveis de concentrado, as concentrações de $\mathrm{N}-\mathrm{NH}_{3}$ se situaram abaixo do intervalo proposto por Mehrez et al. (1977), de 19 a $23 \mathrm{mg} / 100 \mathrm{~mL}$ para a máxima atividade fermentativa no rúmen.

Nos bovinos, as concentrações de $\mathrm{N}-\mathrm{NH}_{3}$ ruminal não foram influenciadas pelos níveis de concentrado (Figura 1). Do mesmo modo, Cardoso et al. (2000b) não observaram alterações na concentração de $\mathrm{N}-\mathrm{NH}_{3}$ ruminal em novilhos mestiços F1 Limousin x Nelore alimentados com cinco níveis de concentrado.

Efeito cúbico na concentração de amônia ruminal também foi verificado em bovinos por Fregadolli et al. (2001) e Geron (2003), que relacionaram o aumento na concentração de amônia ruminal antes do fornecimento da ração ao manejo e ao movimento da pesagem dos alimentos, que geram ansiedade pela refeição e conseqüente estímulo para a salivação ocasionados por fatores sensoriais como visualização do alimento e olfato.

\section{Conclusões}

Dietas com 23 a $63 \%$ de concentrado, com milho moído e resíduo desidratado de fécula de mandioca como fonte de amido, resultam em baixo consumo de matéria seca em bubalinos e, em bovinos e bubalinos, aumentam a digestão ruminal do amido sem prejuízo na atividade dos microrganismos fibrolíticos.

Quando alimentados com concentrado contendo milho moído e resíduo desidratado de fécula de mandioca (amido de baixa e alta degradabilidade ruminal), bovinos utilizam melhor a proteína e o amido em comparação a búfalos, o que sugere maior viabilidade de utilização da associação dessas fontes de amido para bovinos.

\section{Literatura Citada}

AGRICULTURAL RESEARCH COUNCIL - ARC. Report of the protein group of the Agricultural Research Council Working party, on the nutrient requirement of ruminants. London: Commonwealth Agricultural Bureaux, 1984. 45p.

ABDULLAH, N.; NOLAN, J.V.; MAHYUDDIN, M. et al. Digestion and nitrogen conservation in cattle and buffaloes given rice straw with or without molasses. Journal of Agricultural Science, v.119, p.255-263, 1992.

ANGULO, R.A.; NOGUERA, R.R.; BERDUGO, J.A. El búfalo de agua (Bubalus bubalis) un eficiente utilizador de nutrientes: aspectos sobre fermentación y digestión ruminal. Livestock Research for Rural Development, v.17, n.67, 2005. Acesso em: 10/10/2005. Disponível em: <http://www.cipav.org.co/lrrd/ 1rrd17/6/angu17067.htm.>

BARTOCCI, S.; AMICI, A.; VERNA, M. et al. Solid and fluid passage rate in buffalo, cattle, and sheep fed diets with different forage to concentrate ratios. Livestock Production Science, v.52, p.201-208, 1997.

BELEZE, J.F.R. Digestibilidade e parâmetros ruminais de rações com teores de concentrado e adição de ionóforo ou probiótico para bovinos e bubalinos. Maringá: Universidade Estadual de Maringá, 2005. 161p. Tese (Doutorado em Zootecnia) - Universidade Estadual de Maringá, 2005.

BERCHIELLI, T.T.; RODRIGUEZ, N.M.; ANDRADE, P. et al. Eficiência de síntese de proteína microbiana estimada por diferentes marcadores microbianos. Revista Brasileira de Zootecnia, v.24, p.800-809, 1995.

BÜRGER, P.J.; PEREIRA, J.C.; COELHO DA SILVA, J.F. et. al. Consumo e digestibilidade aparente total e parcial em bezerros holandeses alimentados com dietas contendo diferentes níveis de concentrado. Revista Brasileira de Zootecnia, v.29, p.206-214, 2000.

CARDOSO, R.C.; VALADARES FILHO, S.C.; COELHO DA SILVA, J.F. et al. Consumo e digestibilidades aparentes totais e parciais de rações contendo diferentes níveis de concentrado, em novilhos $F_{1}$ Limosin $x$ Nelore. Revista Brasileira de Zootecnia, v.29, p.1832-1843, 2000a.

CARDOSO, R.C.; VALADARES FILHO, S.C.; COELHO DA SILVA, J.F. et al. Síntese microbiana, pH e concentração de amônia ruminal e balanço de compostos nitrogenados, em novilhos $\mathrm{F}_{1}$ Limosin x Nelore. Revista Brasileira de Zootecnia, v.29, p.1844-1852, 2000b.

CECAVA, M.J.; MERCHEN, N.R.; GAY, L.C. Composition of ruminal bacteria harvested from steers as influenced by dietary energy level, feeding frequency and isolation techniques. Journal of Dairy Science, v.73, p.2480-2488, 1990 .

COELHO DA SILVA, J.F.; LEÃO, M.I. Fundamentos de nutrição de ruminantes. Piracicaba: Livroceres, 1979. 380p.

DI LELLA, T.; INFASCELLI, F.; CUTRIGNELLI, M.I.; Rumen degradability and proteic value of feed utilized by buffaloes. Bubalus Bubalis, v.1, p.38-48, 1995.

DIAN, P.H.M. Substituição do milho pelo resíduo de fecularia de mandioca sobre o desempenho, características de carcaça e digestibilidade de bovinos confinado. Maringá: Universidade Estadual de Maringá, 2004. 64p. Dissertação (Mestrado em Zootecnia) - Universidade Estadual de Maringá, 2004.

DIAS, H.L.C.; VALADARES FILHO, S.C.; COELHO DA SILVA, J.F.C. et al. Consumo e digestões totais e parciais em novilhos $\mathrm{F}_{1}$ Limosin $\mathrm{x}$ Nelore alimentados com dietas contendo cinco níveis de concentrado. Revista Brasileira de Zootecnia, v.29, n.2, p.545-554, 2000.

EZEQUIEL, J.M.B. Exigência de proteína e minerais de bovídeos: frações endógenas. Viçosa, MG: Universidade Federal de Viçosa, 1987. 131p. Tese (Doutorado em Zootecnia) - Universidade Federal de Viçosa, 1987.

FRANZOLIN, R.; FRANZOLIN, M.H.T. Efeitos de dietas com polpa cítrica em substituição ao milho em grão no concentrado sobre a degradabilidade e a fauna ruminal em bubalinos. Revista Brasileira de Zootecnia, v.29, p.2109-2118, 2000.

FREGADOLLI, F.L.; ZEOULA, L.M.; BRANCO, A.F. et al. Efeitos das fontes de amido e nitrogênio de diferentes degradabilidades ruminais. 2. pH, concentração de amônia no líquido ruminal e eficiência de síntese microbiana. Revista Brasileira de Zootecnia, v.30, p.870-879, 2001

GERON, L.J.V. Produção e utilização da silagem de resíduo da filetagem de tilápia na alimentação de ruminantes. Maringá: Universidade Estadual de Maringá, 2003. 88p. 
Dissertação (Mestrado em Zootecnia) - Universidade Estadual de Maringá, 2003

GUIMARÃES, K.C.; BRANCO, A.F.; ZEOULA, L.M. et al. Efeito do período experimental sobre a fermentação ruminal e eficiência de síntese microbiana em bovinos alimentados com dois níveis de volumosos. Revista Brasileira de Zootecnia, v.30, p.880-887, 2001

HUNTINGTON, G.B. Starch utilization by ruminants: from basics to the bunk. Journal of Dairy Science, v.75, p. 852, 1997.

ÍTAVO, L.C.V.; VALADARES FILHO, S.C.; SILVA, F.F. et al. Consumo e digestibilidades aparentes totais e parciais de nutrientes em novilhos alimentados com dietas contendo vários níveis de concentrado. Revista Brasileira de Zootecnia, v.31, p.1543-1552, 2002.

JORGE, J.R.V., ZEOULA, L.M.; PRADO, I.N. et al. Substituição do milho pela farinha de varredura (Manihot esculenta, Crantz) na ração de bezerros Holandeses. 2. Digestibilidade e valor energético. Revista Brasileira de Zootecnia, v.31, p.205-212, 2002

KAWASHIMA, T. Role of native ruminants in establishment of sustainable agricultural systems in northeast Thailand. Disponível em: <http://ss.jircas.affrc.go.jp/kanko/ working\%20report/No.30/30-01-10.pdf.> Acesso em: 26/05/ 2004.

KEARL, L.C. Nutrient requirements of ruminant in development countries. Logan: Utah State University, 1982. 381p.

KEARL, L. Exigências nutricionais dos bubalinos. In: RAMOS, A.A. (Ed.) Contribuição aos estudos dos bubalinos. Botucatu: CopyGráfica, 2003. p.47-90.

LADEIRA, M.M.; VALADARES FILHO, S.C.; COELHO DA SILVA, J.F. et al. Consumo e digestibilidades aparentes totais e parciais de dietas contendo diferentes níveis de concentrado, em novilhos nelore. Revista Brasileira de Zootecnia, v.28, p.395-403, 1999.

MARQUES, J.; PRADO, I.N.; ZEOULA, L.M. et al. Avaliação da mandioca e seus resíduos industriais em substituição ao milho no desempenho de novilhas confinadas. Revista Brasileira de Zootecnia, v.29, p.1528-1536, 2000.

MEHRES, A.Z.; ØRSKOV, E.R.; McDONALD, I. Rates fermentation in relation to ammonia concentration. The British Journal Nutrition, v.38, p.437-443, 1977.

NATIONAL RESEARCH COUNCIL - NRC. Nutrient requirements of dairy cattle. Washington, D.C.: National Academy Press, 1988. $158 \mathrm{p}$

NATIONAL RESEARCH COUNCIL - NRC. Nutrient requirements of beef cattle. Washington, D.C.: 1996. 242p

NATIONAL RESEARCH COUNCIL - NRC. Nutrient requirements of dairy cattle. 7.rev.ed. Washington, D.C.: 2001. 381p.

NOCEK, J.E.; TAMINGA, S. Site of digestión of starch in the gastrointestinal tract of dairy cows and its effect on milk and composition. Journal of Dairy Science, v.74, p. 3598, 1991.

PEIXOTO, R.R.; WARNER, R.G. Avaliação da farinha de mandioca como componente de rações para terneiros leiteiros e desaleitamento precoce. Revista Brasileira Mandioca, v.12, p.39-47, 1993.

PEREIRA，J.R.A.; ROSSI, P. Manual prático de avaliação nutricional de alimentos. Piracicaba: Fundação de Estudos Agrários Luiz de Queiroz, 1995. 25p.

PRADHAN, K.; BHATIA, S.K.; SANGWAN, D.C. Feed consumption pattern, ruminal degradation, nutrient digestibility and physiological reactions in buffalo and cattle. Indian Journal of Animal Sciences, v.67, n.2, p.149-151, 1997.

RODRIGUES, V.C.; ANDRADE, I.F.; SOUZA, J.C.D. Avaliação do consumo e da capacidade digestiva de búfalos e bovinos. Ciência Agrotécnica, v.25, p.1406-1412, 2001.

SILVA, D.J.; QUEIROZ, A.C. Análise de alimentos (Métodos químicos e biológicos). 3.ed. Viçosa, MG: Universidade Federal de Viçosa, 2002. 235p.

SIVKOVA, K.; TRUFCHEV, H.; VARLIAKOV, I. Comparative studies on fermentation processes in the rumen and blood content of calves and buffalo calves I. Effect on diet, containing alfafa haylage. In: WORLD BUFFALO CONGRESS, 5., 1997, Caserta. Proceedings... Caserta: 1997. p.312-316.

SOUZA, N.H.; FRANZOLIN, R.; RODRIGUES, P.H.M. et al. Efeitos de níveis crescentes de fibra em detergente neutro na dieta sobre a digestão ruminal em bubalinos e bovinos. Revista Brasileira de Zootecnia, v.29, p.1565-1577, 2000.

TERRAMOCCIA, S.; BARTOCCI, S.; AMICI, A. et al. Protein and protein-free dry matter rumen degradability in buffalo, cattle, and sheep fed diets with different forage to concentrate ratios. Livestock Production Science, v.65, p.185-195, 2000.

TEWATIA, B.S.; BHATIA, S.K. Comparative ruminal biochemical and digestion related physiological characteristics in buffaloes and cattle fed a fibrous diet. Buffalo Journal, v.14, p.161$170,1998$.

TIBO, G.C.; VALADARES FILHO, S.C.; VALADARES, R.F.D. et al. Níveis de concentrado em dietas de novilhos mestiços F1 Simental x Nelore. 1. Consumo e digestibilidades. Revista Brasileira de Zootecnia, v.29, p.910-920, 2000.

TRUFCHEV, H.; SIVKOVA, K.; ZANKOVA, M. Comparative studies on fermentation processes in the rumen and blood content of calves and buffalo calves. II. Effect on diet, containing maize silage. In: WORLD BUFFALO CONGRESS, 5., 1997, Caserta. Proceedings... Caserta: 1997. p.312-316

UNIVERSIDADE FEDERAL DE VIÇOSA - UFV. SAEG - Sistema de análises estatísticas e genéticas. Versão 7.1. Viçosa, MG: 1997. 150p. (Manual do usuário).

USHIDA, K.; LASSALAS, B.; JOUANY, J.P. Determination of assay parameters for RNA analysis in bacterial and duodenal samples by spectrophotometry. Influence of sample treatment and preservation. Reproduction Nutrition Development, v.25, p.1037-1044, 1985

VALADARES FILHO, S.C.; COELHO DA SILVA, J.F.; LEÃO, M.I. et al. Digestão total e parcial da matéria seca, matéria orgânica e carboidratos em novilhos holandeses, nelores e búfalos mestiços. Revista Brasileira de Zootecnia, v.19, p.416-423, 1990 .

Van SOEST, P.J. Nutritional ecology of the ruminant. 2.ed. London: Comstock Publishing Associates, 1994. 476p.

Van SOEST, P.J.; ROBERTSON, J.B.; LEWIS, B.A. Methods for dietary fiber, neutral detergent fiber, and nonstarch polysaccharides in relation to animal nutrition. Journal of Dairy Science, v.74, p.3583-3597, 1991.

VIEIRA, P.F. Efeito do formaldeído na proteção de proteínas e lipídios em rações para ruminantes. Viçosa, MG: Universidade Federal de Viçosa, 1980. 98p. Tese (Doutorado em Zootecnia) - Universidade Federal de Viçosa, 1980.

ZEOULA, L.M.; CALDAS NETO, S.F. Recentes avanços em amido na nutrição de vacas leiteiras. In: SIMPÓSIO INTERNACIONAL EM BOVInOCULtURA DE LEITE, 2001, Lavras. Anais... Lavras: Universidade Federal de Lavras, 2001. p.249-284.

ZEOULA, L.M.; COELHO DA SILVA, J.F.; LEÃO, M.I. et al. Total and partial digestibility in Bos taurus, Bos taurus indicus and buffalo fed on diets with different sources of starch in the presence or absence of urea. 2. Carbohydrates. In: WORLD Buffalo CONGRess, 5., 1997, Caserta. Proceedings... Caserta: 1997. p.286-290.

ZEOULA, L.M.; MARTINS, A.S.; ALCALDE, C.R. et al. Solubilidade e degradabilidade ruminal do amido de diferentes alimentos. Revista Brasileira de Zootecnia, v.28, p.905-912, 1999.

ZEOULA, L.M.; CALDAS NETO, S.F.; BRANCO, A.F. et al. Mandioca e resíduos das farinheiras na alimentação de ruminantes: $\mathrm{pH}$, concentração de $\mathrm{N}_{-} \mathrm{NH}_{3}$ e eficiência microbiana. Revista Brasileira de Zootecnia, v.31, p.1582-1593, 2002.

ZICARELLI, L. Nutrition in dairy buffaloes - alimentazione della buffala da latte. Caserta: Coppia Omaggio, 2001. 66p

Recebido: $14 / 10 / 04$ Aprovado: 30/10/06 